\title{
PENGARUH PAJANAN PARTIKEL KARBOFURAN TERHADAP KELUHAN SUBJEKTIF PEKERJA DI BAGIAN PRODUKSI PT PETROKIMIA KAYAKU GRESIK
}

\author{
Devisnaini Rahmah, Rachmaniyah, Sri Mardoyo
}

\begin{abstract}
PT Petrokimia Kayaku Gresik is a company engaged in the field of pesticides. Its production process is divided into several parts: liquid, powder (granules), solids and biological fertilizers production. The production process includes process of making Petrofur products that use carbofuran raw material that cause dust resulting direct exposure to workers in production section. Identification toward characteristics of production worker showed that some workers did not wear personal protective equipment such as masks and gloves, therefore subjective complaints and health problems appeared.

Research was conducted analytically with cross sectional approach. Dust was measured by using HVDS and questionnaire to 30 people. This study used statistical test of "Chi Square" with $a=0.05$ to determine effect of carbofuran particle on subjective complaints of workers in production section.

Result of the research showed that carbofuran particle level exceeded Ministry of Health TLV of Kepmenkes No.1405/Menkes/SK/XI/2002 by 0.09 and 0.07 . After statistical test, there was no influence between the particles of carbofuran on subjective complaints of workers $(p=0.080)$, work period $(p=0.468)$, nevertheless, there was influence between age and subjective complaints $(\mathrm{p}=0.45)$.

This study concludes that there was no effect of carbofuran particle level on subjective complaints. The company should pay attention on dust control technically, administratively and provide personal protective equipment to prevent complaints and health problems in workers in production section.
\end{abstract}

\section{Keywords: Carbofuran Particle, subjective complaints}

\section{PENDAHULUAN \\ Latar Belakang}

PT. Petrokimia Kayaku merupakan salah satu anak perusahaan PT. Petrokimia Gresik yang bergerak disektor pertanian dengan memproduksi berbagai jenis pestisida. Tenaga kerja sebagai sumber daya manusia amatlah penting peranannya dari suatu kegiatan industry disamping modal dan peralatan. Oleh karena itu tenaga kerja harus dilindungi dari segala sumber bahaya. Bahaya pada lingkungan kerja dapat menimbulkan gangguan kesehatan tenaga kerja akibat dari pemaparan bahan baku maupun bahan buangan dalam proses produksi.

Karbofuran adalah salah satu pestisida karbamat (pestisida yang mengandung gugus karbonat) yang sangat beracun, karbofuran juga biasa di kenal dengan nama furadan. Karbofuran ini digunakan untuk mengendalikan serangga di berbagai tanaman dalam pertanian seperti kentang, jagung, dan kedelai. Karbofuran ini digolongkan kedalam insektisida sistemik, yang maksudnya insektisida ini diserap melalui akar tumbuhan kemudian didistribusikan ke seluruh organ tumbuhan di mana konsentrasi insektisida tercapai (Budavari, S 2011).

Pemeriksaan sebelumnya terdapat beberapa parameter pencemar udara dan bahan yang digunakan yang mempengaruhi kualitas udara dan keluhan pekerja di PT Petrokimia Kayaku Gresik. Parameter-parameter zat pencemar yang terukur adalah $\mathrm{CO}$ (Karbon Monoksida), $\mathrm{SO}_{2}$ (Sulfur Dioksida), $\mathrm{NO}_{2}$ (Nitrogen Dioksida) dan salah satunya bahan formula pembuatan pestisida yaitu Karbofuran.

Penyebaran zat pencemar ini dipengaruhi kondisi meteorologis, yang meliputi kecepatan angin, temperatur, radiasi global, dan kelembaban udara. Dengan meningkatnya jumlah udara limbah pabrik, jumlah zat pencemar berupa gas maupun partikel akan meningkat pula. Berdasarkan data awal yang telah saya peroleh beberapa mengalami keluhan subyektif setelah uji kholinesterase seperti pusing, mual, sesak nafas. Hal ini jika dibiarkan dikhawatirkan menghambat proses produksi. 


\section{Tujuan}

Mengetahui pengaruh partikel Karbofuran di lingkungan kerja tersebut terhadap keluhan subyektif pekerja di bagian produksi PT Petrokimia Kayaku Gresik

\section{METODE PENELITIAN}

\section{Jenis Penelitian}

Penelitian ini termasuk jenis penelitian analitik. Sedangkan berdasarkan waktunya, penelitian ini termasuk penelitian cross sectional.

\section{Populasi dan Sampel}

Dalam penelitian ini yang menjadi populasi dan sampel adalah seluruh pekerja yang berjumlah 30 orang yang ada pada bagian produksi yang menggunakan bahan aktif karbofuran PT Petrokimia Kayaku Gresik.

\section{HASIL PENELITIAN DAN PEMBAHASAN}

\section{A. Hasil pengukuran parameter}

\section{kualitas fisik udara}

Hasil pengukuran parameter kualitas fisik udara yang meliputikadar debu karbofuran, suhu, kelembaban, dan kecepatan angin yang ada di PT Petrokimia Kayaku Gresik sebagaimana ada pada tabel dibawah ini.

Tabel 1.

Hasil Pengukuran Parameter Kualitas Fisik Udara Yang Meliputi Kadar Debu Karbofuran,Suhu, Kelembaban, Dan Kecepatan Angin Di Pt Petrokimia Kayaku Tahun 2015

\begin{tabular}{|l|c|c|c|c|}
\hline Kode Sampel & $\begin{array}{c}\text { Kadar Debu } \\
\text { Karbofuran } \\
\left(\mathrm{mg} / \mathrm{m}^{3}\right)\end{array}$ & $\begin{array}{c}\text { Kecepatan Angin } \\
(\mathrm{m} / \mathrm{s})\end{array}$ & $\begin{array}{c}\text { Kelembaban } \\
(\% \mathrm{RH})\end{array}$ & Suhu $\left({ }^{0} \mathrm{C}\right)$ \\
\hline HV 01 & 0,19307 & 1,28 & 72,1 & 30 \\
\hline HV 02 & 0,1760 & 0,57 & 70,2 & 30 \\
\hline
\end{tabular}

Sumber : Data Primer

Berdasarkan tabel 1, dapat diketahui bahwa jumlah kadar debu partikel karbofuran di lingkungan produksi pestisida PT Petrokimia Kayaku Gresik yang dilakukan pengukuran sebanyak 2 kali yaitu di titik satu 0,19307 $\mathrm{mg} / \mathrm{m}^{3} \mathrm{mg} / \mathrm{m}^{3}$, jumlah kecepatan angin yaitu $1,28 \mathrm{~m} / \mathrm{s}$, kelembaban $72,1 \%$, suhu yaitu $30^{\circ} \mathrm{C}$ dan di titik dua $0,1760 \mathrm{mg} / \mathrm{m}^{3}$, jumlah kecepatan angin yaitu $0,57 \mathrm{~m} / \mathrm{s}$, kelembaban $70,2 \%$, suhu yaitu $30^{\circ} \mathrm{C}$.

\section{B. Hasil identifikasi keluhan subyektif pada pekerja di bagian produksi}

Hasil identifikasi keluhan subyektif pada pekerja di bagian produksi PT. Petrokimia Kayaku sebagaimana ada pada tabel dibawah ini :

Tabel 2.

Hasil Identifikasi Keluhan Subyektif Pada Pekerja Di BagianProduksi PT. Petrokimia Kayaku Tahun 2015

\begin{tabular}{|c|c|c|}
\hline Jenis Keluhan & N & $\%$ \\
\hline Bersin-bersin & 2 & 6 \\
\hline Mata merah & 3 & 10 \\
\hline Batuk & 4 & 13 \\
\hline Pusing & 4 & 13 \\
\hline Gatal pada kulit & 2 & 6 \\
\hline Nyeri Dada & 3 & 10 \\
\hline Sesak Nafas & 4 & 13 \\
\hline Mual & 8 & 26,7 \\
\hline Jumlah & 30 & 100 \\
\hline
\end{tabular}

Sumber : Data Primer

Berdasarkan tabel 2, responden sebagian besar menyatakan mengalami keluhan mual yaitu 8 orang dengan prosentase sebesar
$26,7 \%$, keluhan pusing yaitu 4 orang dengan prosentase $13,3 \%$, keluhan sesak nafas yaitu 4 orang dengan prosentase $13,3 \%$, keluhan 
batuk yaitu 4 orang dengan prosentase 13,3\%, keluhan nyeri dada yaitu 3 orang dengan prosentase $10,0 \%$, keluhan mata merah yaitu 3 orang dengan prosentase $10,0 \%$, paling sedikit responden menyatakan mengalami keluhan gatal pada kulit yaitu 2 orang dengan prosentase 6,7 dan keluhan bersin-bersin yaitu 2 orang dengan prosentase $6,7 \%$.

Hal ini disebabkan karena kadar debu partikel karbofuran pada bagian ruang produksi sudah melebihi NAB. Kadar debu yang terhirup juga sangat mempengaruhi keluhan yang ditimbulkan oleh responden maka semakin berat pula keluhan yang akan dirasakan oleh responden tersebut jika terusmenerus terhirup.

\section{Hasil analisis kadar partikel karbofuran terhadap keluhan subyektif pekerja}

Tabel 3.

Hasil Identifikasi Umur Pekerja Dengan Keluhan Subjektif PekerjaPada Bagian Produksi PT. Petrokimia Kayaku Gresik Tahun 2015

\begin{tabular}{|c|c|c|c|c|}
\hline \multirow{2}{*}{ Umur } & \multicolumn{3}{|c|}{ Keluhan Subjektif Pekerja } & $\begin{array}{c}\text { Jumlah Pekerja } \\
\text { Keseluruhan }\end{array}$ \\
\cline { 2 - 4 } & Ringan & Sedang & Berat & \\
\hline$\leq 40$ tahun & 4 & 3 & 12 & 19 \\
& $(13,3 \%)$ & $(10,0 \%)$ & $(40,0 \%)$ & $(63,3 \%)$ \\
\hline$\geq 40$ tahun & 0 & 6 & 5 & 11 \\
& $(0 \%)$ & $(20,0 \%)$ & $(16,7 \%)$ & $(36,7 \%)$ \\
\hline \multicolumn{4}{|c}{} & $(100 \%)$ \\
\hline
\end{tabular}

Sumber : Data Primer

Berdasarkan tabel 3, responden pekerja industri pestisida PT Petrokimia Kayaku Gresik yang mengalami keluhan subjektif menurut umur $\leq 40$ tahun sebanyak 19 orang dengan prosentase sebesar 63,3\%, dan dikategorikan yang mengalami keluhan ringan yaitu 4 orang dengan prosentase sebesar $13,3 \%$, mengalami keluhan sedang yaitu 3 orang dengan prosentase sebesar $10,0 \%$ dan mengalami keluhan berat yaitu 12 orang dengan prosentase 40,0\%. Sedangkan yang berumur $\geq 40$ tahun sebanyak 11 orang dengan prosentase sebesar $36,7 \%$, dan dikategorikan yang
Berdasarkan uji statistik dengan menggunakan uji Chi square antara kadar debu dengan keluhan subjektif pekerja dibagian produksi industri pestisida didapatkan hasil $0,080>a(0,05)$ yang artinya tidak ada hubungan antara kadar debu karbofuran dengan keluhan subjektif yang ditimbulkan pekerja.

\section{Hasil identifikasi karakteristik pekerja dengan keluhan subjektif pekerja}

Hasil identifikasi karakteristik pekerja dengan keluhan subjektif pekerjapada bagian produksi PT Petrokimia Kayaku Gresik, yang meliputi : umur, masa kerja, alat pelindung diri (APD)sebagaimana ada pada tabel dibawah ini :

3 
Tabel 4.

Hasil Identifikasi Masa Keja Pekerja Dengan Keluhan Subjektif PekerjaPada Bagian Produksi PT. Petrokimia Kayaku Gresik Tahun 2015

\begin{tabular}{|l|c|c|c|c|}
\hline \multirow{2}{*}{ Masa Kerja } & \multicolumn{2}{|c|}{ Keluhan Subjektif Pekerja } & \multirow{2}{*}{$\begin{array}{c}\text { Jumlah Pekerja } \\
\text { Keseluruhan }\end{array}$} \\
\cline { 2 - 4 } & Ringan & Sedang & Berat & 14 \\
& 3 & 4 & 7 & $(46,7 \%)$ \\
\hline$\geq 10$ tahun & $(10,0 \%)$ & $(13,3 \%)$ & $(23,3 \%)$ & 16 \\
& 1 & 5 & 10 & $(53,3 \%)$ \\
\hline 10 tahun & $(3,3 \%)$ & $(16,7 \%)$ & $(33,3 \%)$ & 30 \\
& \multicolumn{3}{|c}{} & $(100 \%)$ \\
\hline
\end{tabular}

Sumber : Data Primer

Berdasarkan tabel, bahwa sebagian besar bekerja $\geq 10$ tahun yaitu 16 orang dengan prosentase $53,3 \%$ yang dikategorikan menurut keluhan subjektifyang mengalami keluhan ringan yaitu 1orang dengan prosentase sebesar3,3\%, mengalami keluhan sedang yaitu 5 orang dengan prosentase sebesar $16,7 \%$ dan mengalami keluhan berat yaitu 10 orang dengan prosentase $33,3 \%$. Sedangkan yang bekerja $\leq 10$ tahun yaitu 14 orang dengan prosentase $46,7 \%$ dikategorikan yang mengalami keluhan ringan yaitu 3 orang dengan prosentase 10,0\%, mengalami keluhan sedang yaitu 4 orang dengan prosentase $13,3 \%$, dan yang mengalami keluhan berat yaitu 7 orang dengan prosentase sebesar $23,3 \%$.

Setelah uji statistik dengan uji Chi square menunjukkan bahwa tidak ada pengaruh antara masa kerja dengan keluhan subjektif yang dialami responden.

Masa kerja adalah lama waktu pekerja dari awal mulai bekerja sampai dengan dilakukannya penelitian.

Tabel 5.

Hasil Identifikasi Penggunaan APD Pekerja Dengan Keluhan Subjektif Pekerja Pada Bagian Produksi PT. Petrokimia Kayaku Gresik Tahun 2015

\begin{tabular}{|c|c|c|c|c|}
\hline \multirow[t]{2}{*}{ Penggunaan APD Masker } & \multicolumn{3}{|c|}{ Keluhan Subjektif Pekerja } & \multirow{2}{*}{$\begin{array}{c}\text { Jumlah Pekerja } \\
\text { Keseluruhan }\end{array}$} \\
\hline & Ringan & Sedang & Berat & \\
\hline Memakai APD Masker & $\begin{array}{c}2 \\
(6,7 \%)\end{array}$ & $\begin{array}{c}4 \\
(13,3 \%)\end{array}$ & $\begin{array}{c}5 \\
(16,7 \%)\end{array}$ & $\begin{array}{c}11 \\
(36,7 \%)\end{array}$ \\
\hline $\begin{array}{l}\text { Tidak Menggunakan APD } \\
\text { Masker }\end{array}$ & $\begin{array}{c}2 \\
(6,7 \%)\end{array}$ & $\begin{array}{c}8 \\
(26,7 \%)\end{array}$ & $\begin{array}{c}9 \\
(30,0 \%)\end{array}$ & $\begin{array}{c}19 \\
(63,3 \%)\end{array}$ \\
\hline & & & & $\begin{array}{c}30 \\
(100 \%)\end{array}$ \\
\hline
\end{tabular}

Sumber : Data Primer

Berdasarkan tabel diketahui bahwa yang memakai APD yaitu 11 orang dengan prosentase $36,7 \%$ dan dikategorikan menurut keluhan subjektif yang mengalami keluhan ringan yaitu 2 orang dengan prosentase sebesar 6,7\%, mengalami keluhan sedang yaitu 4 orangdengan prosentase sebesar $13,3 \%$ dan mengalami keluhan berat yaitu 5 orang dengan prosentase $16,7 \%$. Sedangkan yang tidak menggunakan APD yaitu 19 orang dengan prosentase $63,3 \%$ dikategorikan yang mengalami keluhan ringan yaitu 2 orang dengan prosentase $6,7 \%$, mengalami keluhan sedang yaitu 8 orang dengan prosentase sebesar $26,7 \%$ dan yang mengalami keluhan berat yaitu 9 orang dengan prosentase sebesar $30,0 \%$.
Dari data diatas dapat dilihat bahwa kelompok kebiasaan yang tidak menggunakan alat pelindung diri menunjukkan jumlah responden yang mengalami keluhan berat lebih banyak daripada yang menggunakan alat pelindung diri. Dari hasil uji statistik dengan uji Chi square menunjukkan bahwa tidak ada pengaruh antara pemakaian masker dengan keluhan subjektif yang dialami respoden. Kebiasaan menggunakan alat pelindung diri pada saat melakukan pekerjaan sangat berperan penting karena dapat mengurangi dan mencegah paparan dan jalur masuknya kadar debu dan bahan kontaminan yang lain, yang terhirup pada tempat kerja dengan demikian resiko pekerja mengalami keluhan subjektif menjadi rendah. 


\section{KESIMPULAN DAN SARAN Kesimpulan}

Pengukuran Suhu dan kelembaban di ruang produksi industri pestisida PT Petrokimia Kayaku tidak melebihi Nilai Ambang Batas, sedangkan pengukuran Kecepatan angin dan kadar debu karbofuran di ruang produksi industri melebihi Nilai Ambang Batas berdasarkan peraturan lingkungan kerja menurut Kepmenkes No 1405/MENKES/SK/XI/2002 tentang persyaratan kesehatan lingkungan kerja perkantoran dan industri dan menurut Surat edaran MENNAKER NO SE. 01/MEN/1997

Dari hasil pengujian statistik chi square menunjukkan bahwa keluhan subjektif pekerja terhadap kadar partikel karbofuran dan karakteristik masa kerja serta penggunaan APD terhadap keluhan subjektif menyatakan tidak adanya pengaruh antara keduanya, namun karakteristik umur pekerja terhadap keluhan subjektif menunjukkan adanya pengaruh dikarenakan kelompok usia $\leq 40$ mengalami jalur paparan masuknya bahan kimia terlalu sering dan terhirup pekerja.

\section{Saran}

Sebaiknya perusahaan lebih memperhatikan pengendalian kadar debu karbofuran seperti penggunaan Local Exhaust Ventilation dan Vacuum Cleaner, serta dilakukan penyuluhan dan pemeriksaan pekerja secara rutin dan seharusnya pekerja lebih mengutamakan keselamatan dengan penggunaan APD yang baik dan benar.

\section{DAFTAR PUSTAKA}

Aditya S.A., dan Denny A. 2010. Identifikasi Kadar Debu di Lingkungan Kerja dan Keluhan Subjektif Pernafasan Pekerja Bagian Finish Mill.

Anies, 2013. Mewasdai Penyakit Lingkungan. Jakarta, PT. Elex Media Komputindo.

Anizar, 2011. Teknik Keselamatan Kerja dan Pencegahan Kecelakaan. Jakarta, PT Toko Gunung Agung.

Baron dan Merriam. 1011 : Keracunan Karbamat. WHO

Budavari, S. (Ed.). The Merck Index: An Encyclopedia of Chemicals, Drugs, and Biologicals. Twelfth Edition. Merck \& Co., Inc. New Jersey. 2012.
Kurniawan Deni 2011, Perkembangan Industri di Indonesia.

Fardiaz, Srikandi, 2012. Populasi Air dan Udara. Yogyakarta, Kanisius.

Keputusan Menteri Kesehatan Republik Indonesia, 2002. Tentang Persyaratan Kesehatan Lingkungan Kerja dan industri. 1405/MENKES/SK/2002 dan $\mathrm{ES} / \mathrm{SK} / 2002$

Mila, Siti Muslikhatul, 2010. Hubungan antara masa kerja, Pemakaian Alat Pelindung Pernafasan(Masker) pada Pekerja bagian Pengamplasan dengan Kapasitas Fungsi Paru PT. ACCENT HOUSE JEPARA.C

Moeljosoedarmo, Soeripto, 2011. Higiene Industri. Jakarta, Fakultas Kedokteran Universitas Indonesia.

Mukono,H.J. 2011. Pencemaran Udara dan Pengaruhnya Terhadap Gangguan Saluran Pernafasan, Airlangga University Press.

Mukono,H.J. 2011. Prinsip Dasar Kesehatan Lingkungan, Airlangga University Press.

Notoatmodjo, Soekidjo. 2010. Metodologi Penelitian Kesehatan. Rineka Cipta. Jakarta

Ruchirawat, 2013, Pestisida untuk Pertanian dan Dampak Terhadap Kesehatan

Siswanto, A, 2012. Kesehatan Kerja. Balai Hiperkes dan Keselamatan Kerja Jawa Timur.

Siswanto, A. 2012. Ventilasi Industri. Balai Hiperkes dan Keselamatan Kerja JawaTimur. Departemen Pekerja.

Suma'mur P.K, 2010. Hygine Perusahaan dan Kesehatan Kerja. Jakarta, Sagung Seto

Suma'mur P.K, 2010. Keselamatan Kerja dan Pencegahan Kecelakaan, Jakarta, PT Toko Gunung Agung.

Sudarmo, S. 2014. Pestisida. Yogyakarta, Deresan.

Soedjono, dkk. 2010. Pedoman Bidang Studi Pengawasan Pencemaran Fisik Pada Institusi Pendidikan Tenaga Kesehatan Lingkungan. Jakarta. Departemen Kesehatan RI. 